\title{
La decisión de migrar: el caso de los migrantes mexiquenses*
}

The decision to migrate: the case of the Mexican migrant population

La decisión de migrar: el caso de los migrantes mexiquenses

Recibido el 24 de enero de 2017. Aceptado el 8 de mayo de 2017

\author{
Renato Salas Alfaro** \\ México \\ Norma Baca Tavira*** \\ México \\ Verónica Murguía Salas**** \\ México
}

Para citar este artículo:

Salas Alfaro, Renato; Baca Tavira, Norma y Murguía Salas, Verónica (diciembre, 2017). La decisión de migrar: el caso de los migrantes mexiquenses. Ánfora,

24(43), 39-67 Universidad Autónoma de Manizales. ISSN

0121-6538.

\section{Resumen}

Objetivo: identificar los procesos en los que se gesta la decisión de migrar al extranjero, principalmente, las formas de hacerlo y las restricciones que enfrentan las personas. Metodología: se aplicaron entrevistas a migrantes internacionales del Estado de México, entre diciembre 2012 y febrero 2013. El análisis se realizó en dos etapas del proceso migratorio de los mismos sujetos: cuando partieron al extranjero y cuando retornaron a

\footnotetext{
*Este artículo deriva del proyecto de investigación "La migración internacional de retorno en el Estado de México", desarrollado en la Universidad Autónoma del Estado de México (UAEM), recibió financiamiento del Consejo Nacional de Ciencia y Tecnología (Conacyt)/ Ciencia Básica; inició en octubre de 2012 y culminó en diciembre de 2015.

** Doctor en Ciencias del Desarrollo. Profesor e investigador de la UAEM. Correo electrónico: rnt13@ hotmail.com

*** Doctora en Geografía. Profesora e investigadora en el Centro de Investigacióny Estudios en Movilidades y Migraciones Internacionales (ClyEMMI), en la UAEM. Correo electrónico: bacatavira@yahoo.es

**** Doctora en Antropología Social. Profesora investigadora en el ClyEMMI de la UAEM. Correo electrónico:vero.murguia@gmail.com
} 
sus localidades. Resultados: se encontró que ambos momentos de migración tienen formas particulares: las personas reciben fuertes presiones por su situación económica, emocional y socio familiar; tienen intenciones de mejorar y apoyar a sus hogares; también se verifica la injerencia de actores adicionales e imprevistos; al retorno, se suman los aprendizajes y vivencias que han tenido en el extranjero: añoranza familiar, falta de empleo. Conclusiones: las decisiones de migración se realizan en entornos sociales y familiares y presentan particularidades que escapan la cobertura teórica; por eso, fue necesario acudir directamente a la voz de los migrantes para entender estos procesos de cavilación y las influencias que reciben del entorno.

Palabras Clave: Migración; Decisión de migrar; Migrantes internacionales.

\begin{abstract}
Objetive: to identify the processes which lead to the decision of migrating abroad, principally, how Mexicans do it and the restrictions they face. Methodology: Interviews were performed to the international migrants from the State of Mexico between December 2012 and February 2013.The analysis was conducted in two stages during the migratory process to the same people: when leaving abroad and returning to their localities. Results: the results showed that both moments of migration have particular forms: people are firmly pressured due to their economic, emotional and family situations; they have the intention to improve and support their homes; and additional actors and unexpected events interfere as well. When returning, they bring lessons and experiences from abroad: family homesickness, lack of employment. Conclusions: the migration decisions are made within social and family environments and have particularities that the theoretical coverage misses; therefore, it was necessary to go directly to the voice of the migrants in order to understand such reflection processes and the influences they receive from the environment.
\end{abstract}

Keywords: Migration; Decision to migrate; International Migrant population.

\title{
Resumo
}

Objetivo: identificar os processos nos quais se gesta a decisão de imigrar ao exterior, principalmente, as maneiras de fazê-lo e as limitações que as pessoas enfrentam. Metodologia: entrevistas com migrantes internacionais do Estado do México foram implementadas entre dezembro de 2012 e fevereiro de 2013. A análise foi realizada 
em duas etapas do processo de imigração dos mesmos participantes: quando eles foram para o exterior e quando eles voltaram para suas localidades. Resultados: verificou-se que ambos momentos de imigração têm formas particulares: as pessoas recebem fortes pressões pela sua situação econômica, emocional e sócio familiar, eles pretendem melhorar e apoiar as suas famílias; também se verifica a ingerência de fatores adicionais e não planejados; e ao momento do retorno, juntam-se as aprendizagens e experiências que eles têm tido no exterior: saudade da família, falta de emprego. Conclusões: as decisões de migração são feitas em ambientes sociais e familiares e apresentam particularidades que saem da cobertura teórica; portanto, era necessário ir diretamente à voz dos migrantes para entender esses processos de meditação e as influências que recebem do ambiente.

Palavras-chave: Imigração; Decisão de imigrar; Imigrantes internacionais. 


\section{Introducción}

La decisión de migrar al extranjero se liga al modo de vida que tienen las personas y el que desean tener, al tipo de relaciones familiares, a los estados emocionales, a las oportunidades y condiciones de trabajo y al nivel de ingresos. La migración también se relaciona con la aspiración de ubicarse en entornos con más seguridad, cuando se habita en territorios marcadamente violentos.

Pero las explicaciones sobre cómo ocurre la decisión de migrar son más bien hipótesis y deducciones generales que, si bien remiten a comportamientos, en particular no distinguen, por ejemplo, las heterogeneidades que se presentan en los entornos, ni las razones que motivan la migración en las personas. Sin embargo, a partir de acercamientos con los migrantes y sus familiares, se aprecia una variedad de situaciones que impactan y diversifican las motivaciones y toma de decisiones para migrar.

Es poco lo que se sabe, respecto a cómo se gesta la idea de partir al extranjero, los recursos de los que se valen las personas para migrar y las formas de negociación que ocurren entre los que intervienen en la migración, sea en la promoción o en la restricción del evento. Los análisis pioneros de la migración, sobre todo aquellos con énfasis económico (perspectiva neoclásica), concebían que las decisiones de migración eran individuales en respuesta a la diferencia salarial que se observaba entre regiones. Después, se argumentó que los hogares elegían por consenso a los integrantes con mayores posibilidades para migrar y garantizar envíos económicos que a la postre podrían emplearse para superar restricciones productivas (Stark, 1982).

Otros planteamientos, también desde la economía, enfocan su atención en que la gente decide migrar porque aprecian la mejora en el nivel de vida de quienes ya son migrantes; entonces nace la esperanza de que al migrar puedan mejorar sus vidas (Stark y Taylor, 1991; Izcara, 2010); se plantea, además, que las personas migran para acumular ahorros y activos que pretenden utilizar al retorno (Dustmann y Kirchkamp, 2001; Kirdar, 2007). En otras perspectivas, la migración se realiza para incrementar capacidades productivas ${ }^{1}$ de las personas y los hogares, mejorar los niveles de educación, adquirir activos, especialmente los productivos que pueden sostener el modo de vida y sacarlos de la pobreza (Chambers y Conway, 1992).

Algunas investigaciones de carácter social, encuentran que la historicidad de la migración en lo local impacta los procesos migratorios presentes. Generalmente, los migrantes involucran algún familiar o paisano, con el tiempo la migración se

1. Por ejemplo, capital humano (nutrición, educación, conocimientos, habilidades); capital social (contribuciones a la capilla, comunidad, casa de cultura, compadrazgos); capital técnico (herramientas, tecnología, patentes); capital natural (bosques, ríos); capital financiero (ahorros, inversiones). 
va reproduciendo como parte de la cotidianidad y como estrategia de los hogares para la mejora económica (Dinerman, 1983; Cohen, 2001). La migración también es una vía para obtener reconocimiento social (Estrada, 2008; Reichert, 1981), en los varones es referente de hombría (López, 2003), asimismo, algunos migrantes con liderazgo llegan a intervenir en el desarrollo y política local (Murphy, 2000; Zwania, 2013).

En el Estado de México, la migración internacional es una práctica antigua; se registran migrantes internacionales desde principios del siglo pasado, especialmente en la zona rural del sur de la entidad. Esta práctica sigue siendo mayoritariamente masculina, pero destaca que en las últimas tres décadas se ha ampliado la participación e incluye una amplia diversidad de actores rurales y urbanos; las mujeres se incorporaron con rapidez y constancia desde finales de los años ochenta. Con base en trabajo de campo se establece que la edad promedio de los migrantes mexiquenses del último quinquenio (2005-2010) fue de 28 años, su escolaridad de 9.2 grados acumulados.

En el Estado de México, nueve de cada diez habitantes viven en zonas urbanas (15,000 habitantes o más); la entidad constituye la segunda economía más productiva del país después de la Ciudad de México y, a la vez, registra niveles de pobreza en la mitad de su población. Ésta, es una de las entidades que más empleos genera en México, pero no toda la población vive en condiciones aceptables. La migración al extranjero ha funcionado como opción para contar con trabajo e ingreso. En el medio urbano, uno de cada cuatro tiene empleo antes de migrar, pero aspiran a mejoras económicas y sociales.

Asimismo, la rápida incorporación de mujeres en la migración internacional del Estado de México exhibe cambios socio-económicos en el entorno y en la organización de los hogares de migrantes, esta situación es una tendencia en el medio rural de distintos regiones del país (Arias, 2009), pero en el Estado de México, estos cambios se presentan también en el medio urbano. No hay duda que en las referencias locales de las migraciones está el reconocimiento de los esfuerzos y experiencias de quienes han migrado pero también están siendo reconocidas las referencias de mujeres migrantes que realizan actividades económicas y adquieren mayores márgenes de autonomía.

Sin embargo, las explicaciones sobre cómo ocurren las decisiones de migración se describen de forma genérica, mientras los actos de reflexión y asunción del riesgo de la migración ocurren en las personas y en sus hogares, situados en diversos contextos. En este sentido, con base en entrevistas a profundidad aplicadas a migrantes internacionales del Estado de México, este trabajo expone y discute las formas que adquiere la decisión de migrar, identificando circunstancias sociales, culturales e institucionales que inciden sobre esta decisión; para ello, este estudio contempla dos momentos: cuando parten y 
cuando retornan. Se toman como base de análisis testimonios de migrantes, en lugar de pretender verificar una teoría general, ya que consideramos que los actores - tanto mujeres como hombres - tienen especificidades que los llevan a actuar de manera particular frente a incentivos o adversidades para la experiencia migratoria.

La referencia es el Estado de México, porque es la segunda entidad que más aporta al PIB nacional; cuenta con poco más de 16 millones de habitantes y se considera que su estructura productiva - sustentada en la industria y los servicios- es firme y podría retener a la población. No obstante, la migración al extranjero es creciente, más de un millón de mexiquenses se encuentran en Estados Unidos y anualmente expulsa 220 mil personas (Instituto Nacional de Estadística y Geografía [INEGI], 2016). En este sentido, resulta de interés estudiar sobre fenómeno migratorio mexiquense y, profundizar en el análisis sobre los factores que inciden sobre la decisión de migrar y cómo se construye y negocia esta decisión en los hogares.

Conocer cómo las personas toman sus decisiones es importante. En el área de mercadotecnia este conocimiento ayuda a delimitar características, tiempos, costos y presentación de productos y servicios; en el desarrollo de estrategias para los negocios "ejercitarse" en la toma de decisiones puede significar una ventaja sobre los oponentes (Dixit y Nalebuff, 1991, p. 35). La economía del desarrollo no escapa al interés por comprender cómo se toman decisiones. Un reporte del Banco Mundial (2015, p. 3) señala que el desarrollo de los países y las zonas pobres, puede mejorar si se comprende cómo las personas toman decisiones, porque podrían diseñarse programas de acordes a lo que los sujetos quieren y pueden involucrarse de manera activa.

Para entender estos procesos complejos, es necesario reconocer dos principios generales que guían las discusiones sobre la toma de decisiones. A diferencia de la teoría racional, la cual propone que las personas son exhaustivamente racionales (Davidson, 1963), nuevos enfoques conciben a los sujetos en relación con sus grupos sociales en los que sus decisiones afectan y se afectan por los demás. También existe otra perspectiva que considera que las personas no tienen capacidad ni disposición para analizar todas las opciones de una situación, en cambio, prefieren buscar soluciones conocidas y dentro de su comprensión (Dixit y Nalebuff, 1991; Banco Mundial, 2015; Simon, 1962; 1995; Robbins y Judge, 2009).

Bajo esa referencia, las personas se comportan según sus percepciones sobre lo que creen que es la realidad, en esto influye el entorno (Simon, 1962), al igual que la forma y presentación de la situación en cuestión. En otros casos, es posible que las decisiones se tomen intuitivamente. Como señala Domjan (2010, p. 3), la mayor parte de la vida de una persona no se gobierna por propósitos conscientes, 
sino por procesos mentales que responden al ambiente y operan fuera de la supervisión de la conciencia.

De cualquier forma, en las decisiones intencionales, influyen las actitudes, motivaciones, intereses y experiencia de la persona, pero es imposible que pueda asimilar todo lo que observa y la información existente. Esta limitación para procesar toda la información se denomina racionalidad acotada y sugiere que las personas opten por niveles de conformidad más que de maximización y que, ante la necesidad de tomar una decisión, en lugar de analizar todo, desagregan el problema en partes y se concentran en ciertos estímulos (Simon, 1962/1995). Es decir, se realiza una rápida lectura de la situación y, sobre esta imagen se toman decisiones.

Una vez identificado un problema, la persona se concentra en soluciones que operan como marco general en el entorno. Luego, analiza las que difieren un poco y, al final, elije una que considera buena (Robbins y Judge, 2009, p. 143). Desde luego que en las personas que toman decisiones aparentemente intuitivas, no es algo que se contrapone al análisis racional, más bien, puede complementarse e incluso incrementar la asertividad cuando hay un respaldo de conocimiento e información (Robbins y Judge, 2009, p. 148).

El Banco Mundial (2015) respalda la idea de que las personas son emocionales y no solo racionales, por lo que sus decisiones se influyen por las normas, redes y modelos mentales sociales. Estos elementos determinan aquello que la gente percibe como deseable y posible en sus vidas. En este sentido, utilizan dos procedimientos para decidir: uno rápido que es automático y asociativo y uno lento que es deliberativo y reflexivo.

El pensamiento automático recibe influencia de los modelos mentales heredados, lo que lleva a las personas a simplificar los problemas y tomar información adicional de esas creencias, así cuando piensan en algo, emplean conceptos y categorías, estereotipos y cosmovisiones (Banco Mundial, 2015, p. 4). De esta forma, cuando se quiere transformar una situación, adicional a cambiar el sujeto de la acción, también debe trabajarse en mejorar las prácticas e instituciones sociales asociadas, por ejemplo, combatir la pobreza, implica también luchar contra los discursos y estereotipos relacionados, igual con la migración.

En suma, las personas toman sus decisiones en un marco de racionalidad acotada, recurren en primera instancia a soluciones al alcance de su comprensión en función de sus intereses, emociones y formación. Pero en razón de que se desenvuelven en grupos sociales, reciben influencia de otras formas de vida y otras creencias.

De este modo, comprender las fuerzas que gobiernan las decisiones de migrar al extranjero es importante, porque podrían diseñarse estrategias para 
retener a la población en sus lugares y podría entenderse la función que tienen otros actores y circunstancias en esta y otras decisiones que la población toma cotidianamente. Es conocido que, quienes viven en un determinado entorno, comparten las carencias económicas, violencias, insatisfacciones laborales y valores, pero sólo algunos migran al extranjero; esto sugiere que sobre esta decisión influyen formas específicas del contexto, necesidades, motivaciones, intereses propios y ajenos.

\section{Metodología}

Se aplicó entrevista a 334 personas: 62 mujeres (18.6\%) y 272 hombres (81.4\%), todos migrantes internacionales que residen en el Estado de México. Los entrevistados se escogieron mediante bola de nieve y redes de contactos en localidades urbanas y rurales de 37 municipios ubicados en nueve regiones socioeconómicas del Estado de México (figura 1)². Los migrantes fueron entrevistados entre diciembre de 2012 y febrero de 2013. Se aplicó una guía de preguntas para conocer cómo concibieron sus ideas de migración al extranjero, condiciones emocionales y económicas en las que vivían antes de partir, reacciones familiares que afrontaron, condiciones y sentimientos en que migraron, así como sus temores y objetivos ${ }^{3}$.

2. Acolman, Almoloya de Juárez, Amatepec, Nicolás Romero, San Mateo Atenco, Timilpan, Tonatico, Villa Victoria, Luvianos, Ixtapan de la Sal, Lerma, Jilotepec, Atlacomulco, Coatepec Harinas, Santo Tomas, Axapusco, San Juan Teotihuacán, Otzoloapan, Morelos, Villa del Carbón, Tejupilco, Jocotitlán, Acambay, Nopaltepec, Valle de Bravo, Toluca, Temascalcingo, Tecámac, Tlatlaya, Tianguistenco, Zacazonapan, Otumba.

3. El guión de entrevista se dividió en cuatro módulos. El contenido de cada uno es: A) datos personales, número de viajes a Estados Unidos, año de residencia en su localidad, experiencia laboral nacional, experiencia migratoria de sus padres, situación económica y emocional antes de migrar, opciones de empleo que percibían en su entorno, tipo de vivienda y con quién residían. B) En el proceso de emigración se indagó sobre situación familiar y personal antes de partir, año de emigración, tiempo que tardó en tomar la decisión, cómo se dio el proceso de migración (forma de cubrir gastos, lugar de cruce, historias de cruce de frontera), cómo se dio la consulta en el hogar, negociación, reacciones de los familiares, situación emocional en el momento del cruce. C) Sobre los retornos intermedios se cuestionó sobre los motivos de migrar itinerantemente y el aprendizaje adquirido en cada experiencia. D) Finalmente, se preguntó sobre los motivos del retorno (familiares, laborales, deportación, vejez), así como el aprendizaje adquirido y aplicado para trabajar en el actual lugar de residencia en el Estado de México. 
Figura 1. Municipios de residencia de los migrantes mexiquenses entrevistados

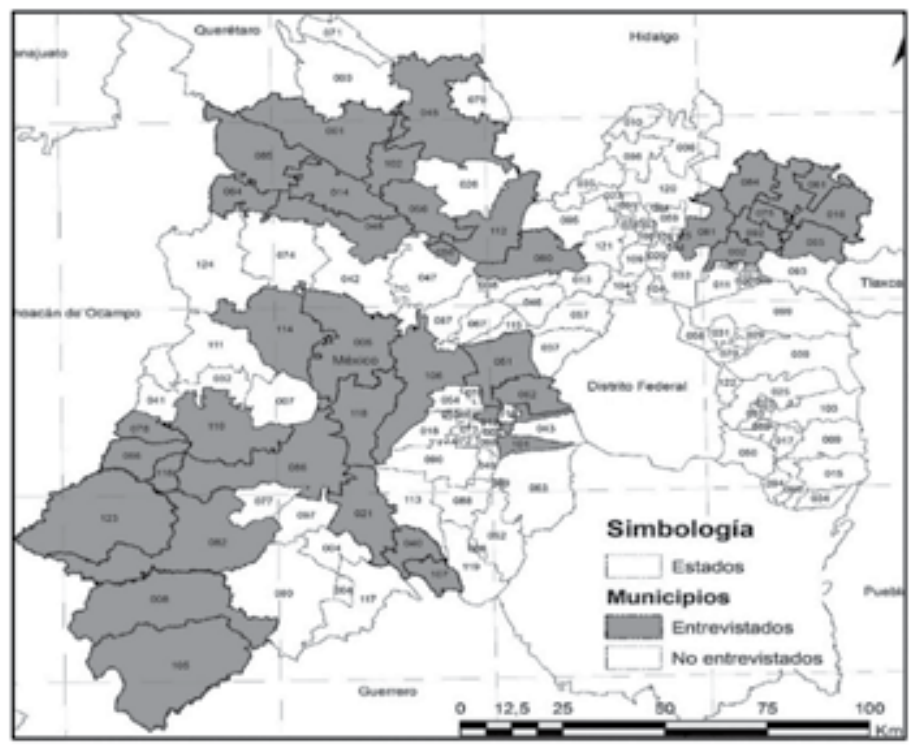

Fuente: elaboración propia

Este análisis se sostiene en la perspectiva centrada en el actor, por lo que sus vivencias conforman la base para entender sus decisiones de migración, la diversidad de ellos es amplia y se eligió centrar la atención en el migrante porque es él quien porta las vivencias migratorias, sin omitir que pertenece a familias de las cuales recibe efectos al tiempo que las influye en las relaciones de su grupo doméstico. Por su parte, el estatus de actor social deriva de su capacidad para procesar y sistematizar sus experiencias, formular estrategias para conseguir objetivos y compartirlas con otros sujetos para actuar en su entorno (Long, 2007).

\section{Resultados}

Los hallazgos se presentan en dos secciones y un comentario final. La primera, revisa los procesos de migración internacional que siguieron los migrantes y la influencia de la familia en la toma de decisiones. En la segunda, se discute la toma de decisiones para regresar a México, circunstancias y formas para tomar estas decisiones, previsiones, la influencia del entorno y otros actores. 


\section{El proceso de migración internacional de los migrantes mexiquenses}

Los migrantes entrevistados, en su mayoría, partieron al extranjero en edades productivas y como indocumentados: tres cuartas partes migraron con edades entre 18-50 años, 20\% tenía menos de 18 y el resto, más de cincuenta años. En promedio, hicieron su primer viaje con 24.6 años (24.4 hombres y 25.7 mujeres); como ha sido referido, en el Estado de México es común que las mujeres migren después que sus maridos, padres y hermanos lo hacen (Baca y Salas, 2015).

Asimismo, los migrantes tenían en promedio una escolaridad de secundaria (9.2 grados); casi dos tercios de ellos poseían mayor escolaridad que la registrada en sus localidades (64.5\% mujeres y $62 \%$ hombres). Aunque los migrantes que provenían del sur, la región de mayor tradición migratoria de la entidad, registraban una escolaridad más baja que el promedio en sus localidades. Otro rasgo es que los migrantes poseían experiencia laboral desde antes de migrar; sólo cinco de ellos no habían trabajado antes de migrar, otras diez eran amas de casa (4.5\%), pero más del $95 \%$ ya había desempeñado algún empleo asalariado, atendía negocio familiar o hacia trabajos independientes ${ }^{4}$; en este caso, más de la mitad se desempeñaba como empleado u obrero. Sólo un tercio realizaba tareas de mayor calificación: encargados de negocio, técnicos o profesionales.

\section{Los motivos para emigrar}

No se identificó una causa específica que empuje a las personas hacia la migración internacional, o que las atraiga hacia sus localidades. En cambio, se advierte que tomaron sus decisiones en un ambiente personal y familiar mezclado de problemas de diversa índole; además de la intervención de parientes y amigos que se involucran en la posibilidad de obtener empleo en el extranjero.

De este modo, quienes no buscaban empleo antes de migrar (estudiantes, amas de casa), más los desempleados, suman 10\%. Otro $30 \%$ señala que no veía opciones laborales en sus localidades; en tanto $60 \%$ menciona que sí había opciones, pero mal remuneradas. La falta de expectativa de desarrollo en lo local es el primer factor que incide en sus decisiones de migración; aunque expresan inconvenientes como la distancia al trabajo, horarios, experiencia y capacitación que les requerían, pero también se reporta discriminación de género, por edad o

4. La experiencia laboral previa: construcción, ventas, obrero, labores agrícolas, chofer, burócrata, costurera, cocinera, mecánico, carpintero, artesano, guardia de seguridad, panadero, zapatero, eléctrico, cantante, peluquero, fontanero. 
por discapacidad. Además había problemas asociados a gastos por enfermedades, sepelios, despidos laborales, reunificación familiar, divorcios.

Los entrevistados señalan que migraron por diversas problemáticas. Pero, ¿qué hay detrás de estas decisiones de migración? ¿Cómo se concretaron? Sus voces describen la decisión de migrar como una mezcla de decisiones e indecisiones que están inmiscuidas diversas dimensiones de sus vidas:

"Yo aquí a la semana ganaba 800 pesos...de lunes a sábado, era empleado de zapatero, igual que mi hermana... aunque mucho antes si nos iba bien como zapateros, pero empezó a llegar el zapato chino y a bajar la venta, hubo muchos despidos, no nos quedó de otra más que irnos a las fábricas y en veces ni así completábamos porque pagan poco, gasta uno mucho en camión, comida, por eso mejor fui al norte" (Juan A., 39 años, San Mateo Atenco, diciembre 2012).

"Me dedicaba a las ventas, agricultura y ganadería, mi papá tenía una tienda y yo le ayudaba, también sembraba y teníamos vacas, chivos. Yo me fui con la idea de traer para hacerme una casa, traerme un carro, eran mis anhelos... tenía la idea de ir y traer dinero hacerme de un negocio propio porque yo era empleado de mi papá y él nunca me dijo que me iba a dar esto o aquello, solo trabajaba para él" (Manuel S., 40 años, San Mateo Otzacatipan, diciembre 2012).

“Nada más le ayudábamos a mi papá a unas vaquitas que tenía por ahí rentando un potrero y allí las ordeñábamos e íbamos comiendo...no teníamos dinero, trabajamos ocho meses en la mina juntando piedra y de fierreros, para el pasaje, estábamos jodidos, por eso se va uno, por la necesidad, no tienes la posibilidad de ponerte un negocio o algo" (Santiago C., 40 años, Zacazonapan, febrero 2013).

Es conocido que, aun con necesidades económicas, la mayoría de la gente no migra, lo cual sugiere que otras circunstancias influyen esta decisión. En este caso, la situación emocional del migrante y su familia (ilusiones y deseos de reunirse con la familia), es el detonador.

"Pues yo tenía 17 años, entonces estaba así pues un poco confundida de lo que quería, me faltaba un año para la prepa, cuando regresé lo vine a terminar aquí, en parte también por los problemas familiares me tuve que ir" (Abigail M., 22 años, Tianguistenco, febrero 2013). 
"Estaba allá mi hermano el mayor, y me llamaba la atención cómo se vestía, su ropa, sus tenis... quería quitarme la tentación de ir... una vez que vinieron mis primos y mis tíos les dije que me quería ir, que si me echaban la mano y me dijeron que sî” (Alberto C., 27 años, Tecámac, diciembre 2012).

"Vivía bien, era profesora, pero mi esposo estaba allá. La primera vez vino por mí, él pagó. Solo iba de visita a conocer y estar con mi familia porque la mayoría de mis hermanos también están allá... Intenté irme con visa, pero me la negaron tres veces y fui indocumentada, pero corrí con suerte pase rápido... estaba lodoso casi dejamos los zapatos, en momentos sentía que me quedaba, mi niña pues de ratos caminaba y de ratos la cargaban los guías así era el acuerdo, ella tenía tres años” (Laura S, 39 años, Temascalcingo, diciembre 2012).

En otros casos, influyeron las intenciones por colaborar en el hogar, mejorar en lo personal.

\begin{abstract}
“Teníamos que salir al día con los sueldos que ganaba mi papá, pero tuvo una situación de salud y se quedó sin trabajo, entonces pues ya no pudimos, bueno mi hermano y yo ya no pudimos continuar con nuestros estudios, entonces tuvimos que salir a buscar trabajo” (Alín M., 22 años, Toluca, diciembre 2012).

"Esa vez la situación económica no era inestable, vivía con mis papás y trabajé de cerillo, nuestra casa era un cuartito, una cocinita de adobe y teja... yo no quería irme, quería trabajar y seguir estudiando, pero no podía y mis papás menos, éramos muchos hermanos, no alcanzaba para todos, tuve que decidir... Recuerdo que me fue a despedir mi papá, mi mamá se quedó llorando, yo iba feliz porque vas a salir, trabajar, conocer, pero triste por la despedida” (Juan M. G., 22 años, Tianguistenco, febrero 2013).
\end{abstract}

\title{
Familia
}

Concebir y dar forma a la decisión de migrar, buscar los medios, comparar entre salir y quedarse, preguntar a los que tienen experiencia es asunto distinto al de emprender la marcha. La decisión de migrar, implica asumir el riesgo en solitario, consultar con los miembros del hogar, imponer la decisión, solicitar la opinión de otros parientes, acatar órdenes de la pareja o los padres. En general, este proceso tiene etapas, en las que la familia tiene un papel preponderante.

En este grupo de entrevistados, 83\% consultó sus intenciones de migrar en su familia, otro 14\% migró sin hacer esa consulta; el resto, fue llevado por los padres, la pareja u otros familiares. Durante la consulta, casi 50\% recibió apoyo 
(moral, económico) de sus familias, el resto señala que recibió negativas o fue llevado por alguien más. Esto difiere con la hipótesis económica de la migración que sostiene que la decisión de migrar se toma por consenso en el hogar y con fines preestablecidos para superar limitaciones productivas (Stark, 1982). En cambio, los entrevistados mexiquenses muestran que concretan las decisiones bajo una racionalidad acotada y con una perspectiva de solución ya probada por otros que han sido migrantes, además de la intervención de otras personas que conforman el grupo inmediato del migrante.

Como se aprecia en los segmentos de entrevista anteriores y subsecuentes, ante la intención de migrar surgen reacciones en torno a sus relaciones personales. En algunos casos, los parientes y coyotes ${ }^{5}$ intervienen para convencer a la familia o para frenar la salida. En casi todos los entrevistados, puede advertirse una valoración o una ruptura entre las perspectivas que tienen los familiares sobre el migrar y aquella que expresan los migrantes, aunque ambos quieren mejorar y salir adelante, cada quien tiene un punto de vista sobre la forma de lograrlo. Al final, con obstáculos o apoyos, estos migrantes salieron al extranjero.

¿Cómo ocurrieron las negociaciones? De acuerdo con lo que señalan los migrantes que consultaron con los miembros de su hogar, además de negociar la salida, también tuvieron que asimilar situaciones emocionales como la tristeza por dejar de ver a sus hijos, parejas y otros familiares. Esta forma indirecta de influencia afecta la decisión de migrar, ya que en algunos casos implicó una postergación de la partida por meses e incluso años, en otros casos, se sobrepusieron y marcharon al extranjero:

“Cuando me iba a ir, platiqué con ellos, mi mamá era la que no quería, mi papá lo veía como una opción de salir adelante por parte de uno, pero mi mamá no quería, al final yo tenía la intención de irme para, de alguna manera, forjarme la vida, no querían pues, pero allí mi cuñado habló con ellos y fue como de alguna manera aceptaron... ya al final mi mamá me dio su bendición” (Moisés B., 40 años, Temascalcingo, diciembre 2012).

"Ella me dijo [la esposa] 'pues está bien si quieres irte, adelante, no estoy de acuerdo porque es mucha distancia y tienes un hijo que atender...' estaba chamaquito tendría como tres años y pues no estaba de acuerdo porque al chavito lo iba a desentender, no lo iba a ver crecer, pero le dije 'es que no hay de dónde agarrar, no tenemos' y le comenté que 'a lo mejor me toca suerte y encuentro un

5. El coyote, es la persona que el migrante contrata para cruzar la frontera de forma indocumentada, esto tiene un costo que actualmente ronda entre cinco y diez mil dólares. según las condiciones del cruce y las facilidades con las que cuenta el coyote. En algunas ocasiones el propio coyote les anima y facilita para migrar y que aquellos le paguen una vez que éste les consigue trabajo en Estados Unidos. 
buen trabajo allá, ella entendió las cosas y se convenció... les di un beso y abrazo a ella y mi hijo, les dije "aquí nos vemos en un año o dos” (José G. G., 40 años, Acambay, diciembre 2012).

"Pues no me dejaban ir, porque como soy el más chico de mi familia, todos me decían "pues qué te hace falta, metete a estudiar", mis hermanos y mis papás me pagaban el estudio, no me dejaban trabajar, me decían "tú dedícate nada más a la escuela, nosotros te vamos a dar para la escuela...” de hecho tuve problemas con mi papá porque no dejaba que me fuera, pero me encapriche como todos mis amigos me platicaban del norte... al final me dieron su bendición, estaban enojados pero me la dieron” (Manuel H., 29 años, Temascalcingo, diciembre 2012).

Entre quienes migraron sin consultar a sus familias, prevalecen las intenciones personales, una idea sobre el norte como lugar de oportunidades y rasgos de inmadurez.

"De hecho, me fui a escondidas de mi papá, nunca les comenté que mi plan era irme a Estados Unidos, les planteé un viaje por estudios, les dije que me iba a ir una semana para que no estuvieran preocupados, así me fui... llevaba el celular, pero no es la misma señal, no sirve, solamente me sirvió para pasar los números. Dilatamos ocho días en pasar, llegando conseguí un teléfono, lo primero que hice fue hablarles a mis papás y les dije, híjole pues mi mamá la verdad se enfermó, mi papá una semana estuvo muy triste, cosas de la vida, después se hicieron a la idea y lo tomaron pues como es, yo ya no iba a regresar” (Abigail M, 22 años, Tianguistenco, febrero 2013).

“Estábamos mal, no teníamos casa, me animó un medio hermano que tenía allá que trabajaba en una compañía de construcción, entonces el trabajo era seguro, yo acostumbrado a ser bien matado y allá de eso se trataba. Él consiguió el dinero y conforme fui trabajando iba pagando...Los padres siempre tratan de que a uno le vaya bien, pero ellos nunca estuvieron de acuerdo en que me fuera por lo mismo de los peligros que había, decían “¿qué tal si te quedas por allá tirado, que tengas sed y que no les den agua?” O sea, los padres tratan de que nos quedemos, pero yo quería sobresalir y por eso me fui” (Alejandro, P. 46 años, Tlatlaya, diciembre 2012).

"Estaba cursando la universidad, no tenía trabajo... No veía opción... tampoco tenía definido qué quería para mi futuro. Faltaba poco para terminar mi carrera por eso tomé esa decisión, quería hacer un rumbo diferente en mi vida, tener 
nuevas expectativas, una visión que me permitiera mejorar. Fue de alguna manera una salida para poder construir algo para mi familia, influyó que me casé y tenía que tener algún modo de sostenerla. Me fui con mi esposa. Platicaba con algunos amigos y primos que tengo en Estados Unidos y me comentaban que había trabajo y manera de tener una mejor vida. Un amigo que crecimos juntos tomó la decisión de irse y vi que económicamente había avanzado, esa fue una de las cosas que me animaron. Yo le había dije que me quería ir, él me habló como al mes y me dijo "pues si te vas a venir tengo todo listo, te vienes en quince días, te apoyo...” ya que empecé a trabajar pagué todo. Pero no es fácil, siempre hay un temor a dejar lo que has tenido muy arraigado, tu familia, tus amigos, son sentimientos encontrados porque pretendes obtener mejor nivel de vida, pero también tienes que pensar en lo que tú estás dejando” (Juan Antonio R., 31 años, Timilpan, diciembre 2012).

Otros migrantes fueron llevados por alguien más, quien tomó la decisión y el riesgo del viaje, es el caso de esposas y menores de edad.

"Mi papá sacó los papeles antes de llevarnos, esa vez yo estaba muy niño y pues la verdad vivía bien, mi papá tenía un empleo como topógrafo de caminos, pero tuvieron problemas con mi mamá, se separaron y le surgió la oportunidad de los papeles. Se fue y nosotros nos fuimos un tiempo con mi mamá y sufrimos bastante porque ella trabajaba y no le alcanzaba. Luego nos llevó con él, apenas había ido al jardín de niños y una parte de la primaria, vivía con mi papá y mis hermanos, en una casa bien, me sentía contento, pero añoraba tener a mi mamá allá conmigo” (Abel, A. 28 años, Tejupilco, diciembre 2012).

"En mi casa, todos han ido al norte, aquí no había trabajo y yo nomás hacía tortillas, las cosas de la casa, era soltera y vivía de lo que mis papás me daban, vivía bien. Mis papás me llevaron, ellos vivían allá, mandaron por mí y me llevaron, cubrieron todo el gasto. Mi propósito era reunirme con mi familia...luego me casé y comencé a trabajar, pero ya era cosa de ponerme de acuerdo con mi esposo" (Olivia, V. 39 años, Toluca, febrero 2013).

Algunos migrantes realizaron acuerdos y asumieron compromisos para obtener la anuencia familiar. Tres de cada cuatro se comprometieron a mejorar la casa, en menor proporción prometieron ahorrar, pagar el estudio de los hijos, comprar carro y otros bienes; quienes solo querían conocer representan $20 \%$. Esta forma de negociar la salida fue importante en aquellos que tenían pareja y en los jóvenes: 
"La crisis económica nos pegaba muy fuerte, eso me obligó a migrar... trabajaba en varias cosas: chofer, mecánico de máquinas de costura, sabía soldar herrería. Éramos cinco hijos y con el sueldo de mi padre, apenas teníamos una casa de adobe y tejas... también me presionó que mi esposa se enfermaba mucho y mi niña igual, y pues no alcanzaba el sueldo que ganaba aquí y como mi abuelo fue migrante, nos platicaba mucho y se fue haciendo el sueño de irme...pero en lo emocional, es muy doloroso pues tiene uno que despedirse de los padres, de su esposa, hermanos, es algo triste para la familia y tú lo recuerdas a cada rato...mi familia no quería que yo me fuera, mis padres de hecho no querían, había muchas personas de mi comunidad allá que habían tenido malas experiencias al cruzar, por eso mi familia no quería, más bien me decían que también aquí en México se podía ganar y que le echara ganas. Pero mi esposa, pues estaba más ilusionada, porque gentes de su comunidad se regresaban con carros, económicamente bien y eso nos alentaba, lograr algo, ese era nuestro sueño, tener nuestra casa, nuestro carro, ella sí estaba un poco animada y a la vez triste porque me tenía que ir...me endeude con unos tíos para que apoyaran los gastos de coyote y avión y me fui con la bendición de mi madre y mi esposa” (Omar G., 36 años, Jilotepec, diciembre 2012).

"Fui porque veía en otros familiares que iban y tenían buena vida, traían carros, construían casa, eso me animó, y quería ayudar a mis papás, sacarlos de la casa donde vivíamos y eso me dio el empujón...Lo platicamos, pero mis papás me decían que no, pues mejor aquí, aunque comiéramos frijoles y eso, pero no querían que me pasara nada o que no fuera a regresar. Yo les insistía de que me quería ir y que quería que me dieran su permiso, ellos fueron pensando y pues decidieron apoyarme... Los gastos fueron de conseguir con familiares, primos tíos que vivían allá y apoyaron, aunque tampoco ellos querían muy bien, pero también platicamos y aceptaron ayudar...A lo mejor no cumplí al cien por ciento, no hice todo lo que quería, pero si lo más urgente, me hicieron una cuenta de ahorro, les ayudé con sus gastos a mis padres, conocí otras cosas, compré un terrenito y construí una casita para vivir con ellos y mis hermanos” (Víctor A. C., 26 años, Toluca, febrero 2013.

\section{Antes y después de 1994}

Aunque la migración internacional en el Estado de México ocurre desde el siglo pasado con el Programa Bracero. Entre los entrevistados, tres de cada cuatro partieron al extranjero a partir de 1994, una cuarta parte migraron antes; 
esto es importante por las condiciones que afrontaron para migrar y los peligros asociados al cruce y búsqueda de empleo.

Hasta antes de 1994, había menor protección fronteriza, las condiciones de cruce eran menos peligrosas, los asaltos y otros peligros casi no se escuchaban. Después de ese año, hubo mayor cantidad de guardias, el cruce se dificultó, los costos y el riesgo se incrementaron; las preocupaciones por la distancia y lo desconocido cambiaron a miedos de morir, secuestros, perderse en el desierto, ahogarse, o no conseguir más recursos.

En México las crisis económicas han sido frecuentes: los hogares han padecido procesos de precariedad del trabajo al tiempo que incremento en el costo de vida. De este modo, aun con mayores peligros y costos, más personas del medio rural y urbano, con mejores calificaciones y experiencia laboral comenzaron a migrar. También las mujeres inician de forma sostenida su marcha al extranjero; antes de 1994 ellas representaban $17 \%$ en el flujo total, a partir de 1994 constituyeron $19 \%$ anual. En cambio, el número de viajes al extranjero que realizaban los migrantes se reduce casi a la mitad: hasta 1993 hacían 3.5 viajes, a partir de 1994, el promedio se reduce a 1.8 viajes por migrante.

Como se aprecia en el cuadro 1, la diversidad de condiciones de vida que había en el Estado de México hasta 1993 y después, ayudan a explicar las decisiones de migración al extranjero. Como fue referido, no todo es necesidad económica. Por un lado, la proporción de migrantes que tenían una "buena vida” y sueldos estables, es similar en ambos periodos de referencia, aunque son porcentajes bajos (13\% y 14\%) ayudan a entender la incorporación de profesionistas, técnicos y otros obreros calificados de origen urbano a la migración internacional, no por falta de empleos, pero sí por la calidad de éstos.

Cuadro 1. Situación previa según periodo de migración, en porcentajes

\begin{tabular}{ccc} 
& H_1993 & 1994_D \\
\hline Emocionado $^{1}$ & 22 & 15 \\
\hline Ayudar a la familia $^{2}$ & 21 & 15.5 \\
\hline Buena vida $^{3}$ & 13 & 14 \\
\hline${\text { Necesidad, } \text { carencias }^{4}}^{\text {Familia de migrantes }}{ }^{5}$ & 38 & 45.6 \\
\hline
\end{tabular}

Fuente: elaboración propia.

$\mathrm{H}$, incluye los años previos hasta $1993 \mathrm{D}$, incluye desde $1994 \mathrm{y}$ años posteriores 1 incluye sentimientos de motivación, buscar la aventura 
2 incluye sentimientos de querer ayudar a sus padres, hermanos, resolver problemas familiares, enfermedades, necesidad para apoyar los estudios de alguien más y propios

3 incluye empleo estable, buen ambiente familiar, ser hijo de familia

4 incluye situaciones de necesidad económica, pobreza, carencias diversas, desempleo, decepción de las oportunidades locales, querer poner un negocio, comprar cosas materiales, camioneta, taxi, deudas, quiebra 5incluye a los que eran familia de migrantes.

Por otro lado, la proporción de quienes atravesaban una mala situación económica incluía 38\% hasta 1993 y 45\% después de ese año; cifras que corroboran el efecto de las políticas liberales, crisis económicas, caídas salariales y deterioro de condiciones de vida de los mexiquenses. También vale decir que, las metas de bienestar asociadas a trabajar, ganar dinero y ahorrar, poner un negocio, pagarse sus estudios, comprar objetos, mejorar sus vidas, independizarse, están entre las razones que tienen para migrar después de 1994; en las mujeres crecen más que en los hombres, porque apenas inician en estos años su migración.

Otro rasgo es que 63\% de los entrevistados que migraron hasta 1993, señala que tardaron entre una semana y un mes cavilando y animándose, a partir de 1994, solamente 50\% de ellos tomaron este tiempo, la otra mitad tardó meses y hasta años en la reflexión. En las mujeres es más visible ese cambio; hasta 1993, tres de cada cuatro mujeres tardaban en decidirse entre una semana y un mes, a partir de 1994, sólo una de cada tres tomaba ese tiempo, las demás tardaban meses y años cavilando.

¿Cómo se filtran en el hogar estas condiciones de migración? En este caso, las voces de los migrantes que partieron al extranjero hasta 1993, develan estas interrogantes:

"Me fui por la familia, aquí estaba muy crítico, tener un futuro, aquí no se puede y pues al principio se siente feo, pero vas con ese valor de ser alguien...quería hacer una casa, tener un carro, luchar y echarle ganas, ya me fui grande de edad, ya había andado en muchas partes del país: Aguascalientes, Reynosa, Guadalajara, Colima. Era chofer, ayudante de albañil y algo de mecánico. Vivía con mis padres y apenas teníamos un cuarto de adobe. Allá en Los Ángeles tenía unos primos y con ellos me fui, me recibieron, pero yo pasé solo, escondiéndome por el cerro con miedo y eso, no me descubrieron gracias a Dios, en aquél entonces era más fácil, no había tanta policía y la verdad pues logré pasar” (Enrique J. S. 60 años, Santo Tomas de los Plátanos, diciembre 2012).

"Desgraciadamente aquí no se puede hacer nada, allá en aquel tiempo había forma de hacer un poquito más para la familia, para mis papás, aquí es un poco difícil, estaba mal pagado no había mucho trabajo. No había recursos para sobrevivir, la 
primera vez le pensé un poco, porque estaba recién casado. Mi hermano ya estaba allá, se fue por problemas económicos y él iba a sacar su residencia, nos fuimos con él y por él fue que agarramos esos papeles, la mica de los diez años, por él fue. Nomás la primera vez crucé por Piedras Negras de mojado, ya después crucé por Tijuana con papeles. Se sufre bastante y hasta se llora en el camino. Platiqué con mi esposa y mis papás, ellos aun vivían, toma uno la decisión y pues en el nombre de Dios y adelante. La familia cuando uno se va se queda llorando porque no sabe lo que pueda pasar en el camino, en el trayecto, no sabes si vaya a regresar uno" (José P., 62 años, Tejupilco, diciembre de 2012).

Los que salieron al extranjero a partir de 1994, enfrentaron condiciones difíciles, sus familias sabían de los riesgos y se oponían. Narran mayores dificultades, pero se aprecia que algunos migrantes maduraron y tuvieron cambios personales que emplean en su cotidianidad.

"Reprobé un semestre, tenía miedo de dejar la familia con la que siempre había estado y siempre estábamos juntos, teníamos una situación económica media, no mucho, lo mío fue como una aventura. A lo mejor había oportunidad para buscar un trabajo, pero en ese momento de inmadurez me fui, la idea de irme nació cuando reprobé el semestre, en ese entonces tenía familiares allá que me hicieron la invitación, me prestaron dinero y solventaron, allá teníamos que pagar. A esa edad dije "pues vamos a ver que hay por allá”. Mi familia me apoyó, para ver si allá recapacitaba y maduraba, me decían "vete, porque con eso quizá vas a recapacitar para ver si valoras lo que no aprovechaste así que vete”. La mamá, las mujeres por lo regular son así, entonces me fui... fueron dos ocasiones que intenté pasar, en la primera nos regresaron, tenía ganas de llegar y reflexionaba ¿por qué estoy aquí? ¿Qué hago aquí? Pudiendo estar a lo mejor en la casa si hubiese seguido la escuela, a lo mejor terminando una carrera; mucho miedo se sentía porque caminas y no sabes qué hay más adelante, qué te puede pasar o a quién le vas a contar. El miedo siempre está presente y, de alguna forma, maduras" (Roberto, G. 34 años, Jocotitlán, diciembre 2012).

"Con la familia la relación era buena, vivía con mis papás, en el trabajo no tanto, me fui triste porque dejaba a mis papás, pero iba a un país a progresar, ¿de dónde iba a sacar pues recursos para hacer algo aquí? Yo llevaba en mente hacer una casa, amueblarla, tener un poco de dinero en el banco... aunque mi familia tenía temor porque no sabían lo que podía pasar, si podía pasar o no, yo también no sabía cómo era cruzar, no sabía qué era lo que me iba a pasar, no sabía cómo iba a ser el viaje... La primera vez que me fui, cubrió los gastos una de mis hermanas, 
ella me ayudó también allá para comprar ropa, zapatos. Esa vez le pensé como dos meses. Yo le comenté a mi papá, me senté con él y le dije "pues sabe qué papá yo me quiero ir pa' Estados Unidos y quiero que me dé permiso, quiero saber qué piensa de eso". Él me dijo "bueno pues si tu tomaste la decisión, adelante, no te puedo decir que no, porque yo no te voy a dar lo que tú vas a ir a ganar allá, entonces ya tomaste la decisión pues esperemos que te vaya bien..." llegando allá me puse a trabajar, luego, estuve trabajando dos años sin descansar y fue que logré mi objetivo de hacer mi casa” (Araceli R., 33 años, Temascalcingo, diciembre 2012).

"Mi esposo no estaba y yo tenía que dejar solos a mis hijos, en la mañana los tenía que ir a dejar a la escuela y ya regresaba para ir a trabajar, entrar a las ocho, era costurera, después regresaba por ellos. Cuando decido irme, me sentía mal porque tenía que dejarlos, pero sentía bien porque tendría qué ofrecerles. Quería tener un techo que ofrecerles, más que nada. Me fui para ayudarle [esposo] y que pudiera estar más pronto aquí, él se había ido primero, porque aquí la situación era muy difícil...yo conseguí para mis gastos con uno de mis cuñados, porque como él estaba allá, pues él me mandó mi boleto y todo eso, él tuvo que conseguir dinero. En ese tiempo estábamos construyendo la casa y él estaba mandando. Mi esposo no quería que yo me fuera porque tendría que dejar a mis hijos, pero le dije "que así tendríamos algo que ofrecerles, teníamos que darles un techo, su escuela...” Al final mis hijos se quedaron con mi papá y mis hermanas, mi papá no quería que me fuera, porque mis hijos pues implica mucho, pero me dijo "si ya lo decidieron, pues adelante, yo te apoyo con tus hijos", nomás un tiempo estuve allá porque como decía mi esposo "no podemos dejarlos más tiempo solos..." le echamos ganas para ahorrar, no malgastar el dinero y seguir con nuestros planes, ya mis hijos tienen casa, uno terminó su carrera, las otras dos, una es madre soltera, la otra se juntó, pero están por terminar sus carreras. En sí, todo lo que tenemos lo hicimos allá, porque aquí desgraciadamente no se puede hacer nada" (Claudia V., 42 años, Tianguistenco, diciembre 2012).

\section{La decisión de retornar}

Regresar es volver a migrar, volver a tomar la decisión, volver a comparar, cavilar, allegarse de información y valor para enfrentar de nuevo las condiciones de vida que una o más veces les empujaron a partir. Como señala Ranciere (2010), el poder institucional en una sociedad legítima unos intereses e ilegítima otros. Esto es, los migrantes no tienen cabida, pero retornan y con eso vienen a buscar un lugar desafiando su exclusión (educativo, laboral, seguridad social, espacios 
de opinión). Su retorno fricciona y desafía esa sociedad y esas condiciones de vida, porque sea por voluntad o forzados, traen capacidades, conocimientos, escolaridad, otro idioma, ahorros, vivencias y una serie de rasgos inherentes a sus personas que pueden emplear a su retorno.

¿Cómo ocurre la decisión de migración hacia México? ¿Cómo interviene la familia que reside en el extranjero y aquella que se encuentra en México? ¿Cuál entorno es el que rodea la gestación del retorno? Estas son algunas interrogantes que ayudan a entender otro momento en que los migrantes toman decisiones en el proceso de la migración internacional.

Entre los entrevistados destaca que para quienes hicieron varios viajes al exterior, si bien fue difícil tomar la decisión de regresar definitivamente a la entidad, una vez estando en México, la inserción fue difícil y con mayores problemas. Pero al retorno, las costumbres adquiridas y la nostalgia por los dólares y comodidades, presionan la exigencia de mejores condiciones de empleo y servicios en sus localidades. De cierta manera, esta es una forma de fricción con sus entornos y una manifestación de diversos duelos, que algunos migrantes traen consigo y que les restringe su inserción (Bautista et al., 2016).

$\mathrm{Al}$ no encontrar condiciones similares a las que dejaron atrás, sus intenciones de permanecer flaquean y algunos vuelven al extranjero. "Me acostumbré a ganar dinero, cuando regresaba no había la posibilidad de nada, más que nada lo económico hace falta, creo que allá se gana un poco más y se vive mejor en ese aspecto, por eso se regresa uno" (Antonio L., 35 años, Temascalcingo, diciembre 2012). Similar testimonio ofrece Ricardo, "me formé un estilo de vida allá, muy diferente a la de aquí, cuando vienes ya no te acostumbras fácilmente a volver a lo de antes, te da por regresarte, le piensas, pero acá no hay nada y ya tenía allá un trabajo, el departamento que rentaba, amigos..." (Ricardo G., 29 años, Atlacomulco, diciembre 2012).

Otro migrante retornó para graduarse de una carrera profesional; sin embargo:

"En la segunda vez [la última] me fui porque ya me había titulado acá, tenía una opción de trabajar, pero pues uno se queda acostumbrado al buen sueldo...cuando estaba en mi proceso de titulación, vino el que era dueño del lugar donde yo trabajaba, pasó a la casa a visitarnos con su esposa y me volvió a ofrecer trabajo; me dijo, "sabes, échame la mano, compré otro negocio..." Se me hizo fácil porque sabía que iba a llegar con el trabajo y mejor pagado, entonces era muy tentativo. Le dije a mi esposa "vámonos y nos regresamos con mi niño" (Miguel Ángel, 32 años, Jocotitlán, diciembre 2012). 
Ya con experiencia migratoria, no sólo la falta de opciones influye, también los forcejeos entre la nostalgia por los dólares, comodidades y oportunidades del extranjero, contra la falta de empleo, apoyos para emprenderlos y bajos salarios, se suman otras intenciones:

"Pues porque el viaje inicial, digamos fue de prueba, a la segunda y tercera vez dije ya conozco, ya sé trabajar en algunas otras cosas, ya espero poder encontrar mejor empleo, ya no voy a llegar a estar escondido, temeroso de no encontrar, ni poder salir, iba un poquito más confiado en poder hacer más dinero, y repito, nunca fue mi intención irme a establecer allá, pero sí irme a juntar un poquito más de dinero, irme a hacer una casa tal vez y traer algo de dinero" (Efraín S., 38 años, Toluca, febrero 2013).

"Ya que estoy aquí, lo que más trabajo me cuesta son los camiones, no me gusta andar en camión, se llenan, no va uno a gusto, pero eso es normal... he mirado que si hay futuro, pero no hay dinero, capital para emprender un negocio, siento que echándole ganas puedo poner uno ....allá aprendí a poner pisos, loseta, con herramienta es fácil, si no tienes herramienta se dificulta, puedo hacer todo, nomás que llegue la oportunidad y tenga mi herramienta...lo del campo también, pues aquí cada quien trabaja su tierra, pero no hay mucho y pagan barato...en lo de manejar la maquinaria hasta ahorita no he encontrado" (Isaac G., 30 años, Tecámac, diciembre 2012).

\section{El retorno}

Ninguna persona de las entrevistadas retornó por una sola causa. Sus narraciones mezclan diversas razones para regresar a sus localidades, destacan: la crisis económica del extranjero, querer reunirse con la familia, criar a los hijos en México, ya no sufrir en el extranjero, casarse o arreglar documentos, miedo a la deportación, añoranza y sentimiento de volver:

"Las condiciones económicas habían disminuido, trabajamos por horas, trabajaba una cantidad pequeña en ese momento, y tenía un auto, entonces decidí venderlo y con ese dinero regresar, aparte ya tenía un poco de dinero en México, y ya sentía la necesidad de visitar a mi familia, de cierta forma extrañaba un poco regresar. Desde que me fui, había tenido ese objetivo, de regresar en algún momento, y creí que las condiciones, pues al tener poco trabajo, pues eran idóneas para ya volver... pero también me comunicaba seguido con mi familia, por celular, la comunicación fue buena, continua, nunca paso más de un mes sin que les llamara. El otro medio es el correo electrónico, ese más que nada fue con mi hermana, en 
muchas ocasiones lo realizaba de esa manera, a veces por video llamadas" (Alberto G., 27 años, Temascalcingo, diciembre 2012).

"Nació mi otro bebé, yo lo daba a cuidar a la baby-sitter pero ella no me le daba de comer, el niño se empezó a ponerse malo, tenía como cinco o seis meses de nacido, y cuando yo le quería dar la comida, ya no quería, no sé si porque su estómago ya se estaba acostumbrando a no tener comida, ya después la baby-sitter tampoco lo quería, me lo devolvía, entonces esa fue la razón por la que yo quise regresar, dije "no puedo seguir trabajando y dándolo a cuidar y se me puede algún día morir, mejor regreso a México”... encontré rápido trabajo y podía cambiar si no me gustaba, podías irte a otro, en la última ya era difícil encontrar otro si te salías de uno, tenías que meter aplicaciones, te daban cuatro horas y no pidas más. Sin otro trabajo, esas horas servían nomás para pagar la renta, el teléfono y la gasolina del carro, así no rendía estar allá” (Araceli R., 33 años, Temascalcingo, diciembre 2012).

Uno de cada diez migrantes señala que en el extranjero sufrió abusos y discriminación de capataces, sobre todo de origen hispano. Son pocos los que pasaron por esta situación, pero dan una idea de lo que ocurre en sus empleos. También señalan que sus problemas de actitud, falta de costumbre a las normas laborales y desadaptación generaba las fricciones.

"Me decepcioné de allá, porque con varios patrones, trabajábamos hasta quince días y no nos pagaban o luego nos pagaban con préstamos, la última vez que trabajamos ya nos debían casi lo de dos meses y se fueron con el dinero de los trabajadores, éramos como treinta, después nomás le alcanzaron a quitar para darnos creo que mil dólares a cada quien, pero nos quedó a deber todavía mucho. Con eso yo me vine, los demás todavía se quedaron” (Víctor R., 30 años, Otzoloapan, diciembre 2012).

Asimismo, sobre el migrante actúa la imagen familiar de quienes se encuentran en México, sea porque los extrañan, les reclaman su regreso y otros atenuantes. También los familiares que residen en el extranjero inciden esta decisión, ora por la buena, ora por imposición. Por ejemplo, la señora María señala que su retorno fue "porque a él [esposo] unas gentes que trabajaban en el hotel le echaron la migra y lo sacaron para Nogales, cuando vuelve a pasar, ya le habían quitado el trabajo, entonces me dijo que me viniera para poderse mover a otro estado... ya quería venirme, pero también me regresé por mis hijos, para cuidarlos mejor acá” (María L., 46 años, Santo Tomas, diciembre 2012). 
Pero al retorno, los migrantes tienen rasgos diferentes. La presión que les significó enfrentarse a nuevas necesidades socioculturales, diversas violencias y vivencias adversas en el cruce, la estancia socio-laboral en el extranjero y su nueva cotidianidad, los llevó a desarrollar actitudes y acciones para adaptarse al extranjero. Esta es una reacción natural de los seres vivos. Al respecto, se señala que, los seres vivos desarrollan actitudes de alerta, amistad, enojo, según el ambiente que los rodea; el aprendizaje transforma sus respuestas en distintas habilidades que antes no poseían o no las veían como tales, al emplearlas y sobreponerse, pueden identificar sus capacidades y desarrollarlas (Domjan, 2010, p. 259). En este sentido, los migrantes desarrollaron diversos conocimientos, capacidades socioculturales y actitudes personales; ellos mismos mencionan que aprendieron a valorar sus familias, amigos y libertad que tienen en México. Sólo uno de cada diez señala que volvió en peores condiciones de las que tenía antes de migrar:

"Mejoré muchas cosas, a ser responsable, apreciar a tu país aunque las cosas no son como tú quieres, lo extrañas y cambias para querer llegar a ser otro y poder cambiarlo... como no eres de allá, te tienes que adaptar a sus reglas, son personas ordenadas, por ejemplo si vas a dar vuelta en tu auto, tienes que anunciar, si vez un animal cruzando tienes que esperar que pase, allá le llaman a la policía... es bonito, pero estás solo, desde que mi papá se regresó a México, ya me había acostumbrado a platicar y estar con él, porque allá cada quién ve por sus cosas, si tienes comes, si no, pues no. Nadie te anda preguntando. Tienes miedo a que te arresten, que te echen a migración, así es allá... en una ocasión dije "me voy para México" y compré mi boleto, pero llegó el tiempo y lo dejé perder, tardé otro año en comprar boleto y me vine. No pensé "me voy a ir en un mes o dos meses", no lo planee, fue en el instante de locura, fue sin pensarlo, se siente feo decir "me voy en un mes" y seguir conviviendo, que se llegue la fecha, por eso solo dije "compro mi boleto y me voy" (Omar B., 23 años, Morelos, diciembre 2012).

"Estuve muy poco tiempo, duré poquito por mi hija y mi esposa, extrañaba a mi familia, la verdad fue una decisión rápida, nomás compre los boletos, unas maletas y vámonos... las extrañaba, hablaba por celular diario y por internet con mi mamá, mis hermanos, mi esposa... Otro motivo fue que mis hijos no padecieran lo que uno, porque cuando uno está chico y no están los papás, no es bueno... la otra, es que te sientes encerrado porque allá es puro trabajo, del trabajo a la casa y de la casa al trabajo, nomás estar piense y piense cuanto voy a ahorrar, cuanto voy a mandar...no hice mucha economía pero aprendí un idioma que se usa en todo el mundo, y tengo una mentalidad diferente a la gente de aquí...Cuando regresé 
terminamos la casa que dejó mi papá, y ya, porque no traía mucho recurso” (Abel A., 28 años, Tejupilco, diciembre 2012).

Algunos consideran que gestionan mejor la problemática familiar, aunque en muchos de ellos cambió la situación civil y eso mismo influyó en tener otra perspectiva. Otros transitaron de adolescentes a la adultez, se convirtieron en padres de familia. Como señalan:

"Ir al norte sirvió porque allá mejoramos los aspectos familiares, tener más acercamiento hacia nosotros mismos. Antes había cosas que no platicaba con ellos, ni ellos a mí, entonces hemos tenido eso. Nos ayudó a valorarnos más y tener más comunicación ya aquí entre todos" (Rodrigo V., 32 años, Nicolás Romero, febrero 2013).

"Me hizo cambiar un poco, porque a mis hijos y esposa los trató diferente. Los respeto un poco más en ya no decirles cosas, inculcándoles que trabajen y que hagan lo que les toca y que las hagan bien, porque yo como su padre las estoy tratando de hacer bien, que estudien es lo más importante, porque hasta allá te sirve el estudio... con el estudio aprendes más rápido inglés, más rápido de lo normal y tener más trato con gente de allá, estar más relacionado y hacer más [patrimonio] que quienes llevan más tiempo yendo” (Ezequiel B., 49 años, Valle de Bravo, diciembre 2012).

"En la familia somos iguales que antes, cariñosos relajos, sociables, pero nomás entre nosotros, así éramos muy juntos y apegados, por eso en Estados Unidos yo sentía ese hueco, las ganas de regresar...en esa parte no cambié nada, pero me hice un poco más responsable, más maduro, más ahora como jefe de familia, ya quedó atrás la inmadurez, hay que atorarle a las responsabilidades" (Roberto G., 34 años, Jocotitlán, diciembre 2012).

\section{Conclusiones}

El estudio concluye que, si bien una minoría migra por su cuenta, en general las decisiones son grupales, negociadas en familia, con distintos argumentos e intervención de otros actores y circunstancias como el miedo, estrés, creencias religiosas y costumbres socializadas. A la vez, esta decisión presenta rasgos específicos en cada caso, lo que restringe el uso de teorías generales tanto de 
migración (Stark, 1982; Dustmann y Kirchkamp, 2001; Kirdar, 2007; Izcara, 2010), como de toma de decisiones (Dixit y Nalebuff, 1991).

Ninguna de las teorías revisadas cubría los aspectos particulares del migrante (además, no podría ni tendría por qué hacerlo). La condición humana es compleja para ser modelada. No se podría derivar de estas teorías una explicación que pudiera resolver el dilema de quedarse en la localidad o marchar al extranjero o de volver a sus localidades, menos aún al considerar que si bien todos son migrantes, cada uno atravesaba una situación económica, social y familiar particular en diversas etapas del proceso migratorio.

Los enfoques sobre toma de decisiones aciertan en la idea de que las personas deciden en ambientes inciertos, recurren a soluciones inmediatas, reciben influencia de otros actores y tomen decisiones de forma intuitiva (Domjan, 2010); sin embargo, las incertidumbres asumen diversas formas que implica una mirada singular cada decisión; por ejemplo, la mujer que retorna por miedo a estar sola después de que deportaron al marido, el estrés de que los hijos tengan accidentes, la angustia de ser detectados y deportados, entre otros. Esto también evidencia que el entorno social es un factor que influye en gran medida para la toma de decisiones, lo cual se lleva a cabo por dos procedimientos: el rápido que es automático y el lento que es reflexivo (Banco Mundial, 2015).

En conjunto, parientes y amigos, circunstancias económicas, problemas emocionales e inmadurez, decepción e inestabilidad laboral, problemas con la justicia, expectativa de aventura y deseos por conocer, posibilidad de encontrar mejores sueldos, empleos y condiciones de vida, influyen para que las personas decidan aceptar una opción de vida fuera de su país. No obstante, hay que aceptar que, si bien las causas de la migración son múltiples y particulares, la necesidad económica manifiesta en diversas maneras, es la razón que más interacciona con las demás circunstancias.

En cambio, la decisión del retorno se motiva por extrañar la familia, miedos, estrés, intenciones de emprendimiento, entre otros que se conjugan con la experiencia migratoria, conocimientos laborales y nuevos activos acumulados, la intención de iniciar de nuevo en sus localidades. Tanto los motivos de migrar como de regresar, muestran la heterogeneidad de circunstancias por las que pasa cada migrante entrevistado en entornos específicos, situación que ayuda a distinguir el enfoque centrado en el actor (Long, 2007).

El caso mexiquense muestra que varias fuerzas se friccionan con las intenciones personales y familiares por salir al extranjero; en este caso, las noticias sobre los peligros del cruce, nostalgia de separarse de sus hijos, carencia de recursos para sufragar sus viajes, falta de contactos, miedo e inseguridad a lo desconocido. Todos los entrevistados fueron migrantes internacionales y 
retornados, es decir, lograron sobreponerse a las circunstancias que se oponían a su migración y retorno.

En los testimonios incluidos en este trabajo, se desprende que, en la toma de decisiones, al menos dos motivaciones forcejeaban. Por un lado, las intenciones, pensamientos, ilusiones de buscar una mejor vida, conocer lugares y costumbres, aprender otro idioma, tener ahorros, las circunstancias de su entorno, el testimonio y los logros de otros migrantes que les escuchan, les comentan y les comparan oportunidades y falta de ellas. Por otro lado, sus temores a lo desconocido, peligros, posibilidad de algo trágico, dudas sobre la verdadera vida del norte, posibilidades de no lograr nada, perder la familia, vicios y muertes de otros migrantes. En ambos tipos de situaciones, intervienen otros actores, éstos a su vez traen sus propias cavilaciones y creencias que se suman como motivadoras o como inhibidoras en el proceso de la toma de decisiones.

\section{Referencias}

Arias, P. (2009). La pluriactividad rural a debate. En Hubert De Grammont y Luciano Martínez (Comps.). La pluriactividad en el campo latinoamericano (pp. 171-206). Quito, Ecuador: Flacso.

Baca, N. y Salas, R. (2015). Configuraciones familiares y de género en un contexto de alta migración internacional en el sur mexiquense. En Reyes, P. (Coord.). Perfil de las familias y los hogares del Estado de México (pp. 123140). México: Porrúa/Universidad Autónoma del Estado de México.

Banco Mundial (2015). Informe sobre el desarrollo mundial 2015: Mente, sociedad y conducta, Washington D.C., Banco Mundial.

Bautista, D., Salas, R., Jiménez, Y. (junio, 2016). Migrantes internacionales del Estado de México: una mirada desde el duelo migratorio y el sentido de la vida, Sociedades y Desigualdades, (2), 75-88. Universidad Autónoma del Estado de México,

Chambers, R. y Conway, G. (1992). Sustainable rural livelihoods: practical concepts for the 21 st Century. Sussex, University of Sussex.

Cohen, J. (2001). Transnational migration in rural Oaxaca, Mexico: dependency, development and the household. American Anthropologist, 103(4), 954-967. 
Davidson, D. (1963). Actions, reasons and causes. Journal of Philosophy (60), 685-700.

Dinerman, I. (1983). El impacto agrario de la migración en Huecorio. Relaciones, 4.(15), 29-52. Zamora, El Colegio de Michoacán.

Dixit, A. y Nalebuff, B. (1991). Pensar estratégicamente, Barcelona, Antoni Bosch.

Domínguez, M. y López. L. (2009). Estudio de impacto de las remesas, Bejucos Tejupilco. En Baca N., Herrera. F. y González R. (Coords.). Migración, democracia y desarrollo. La experiencia mexiquense (pp. 175-187). Toluca, Instituto Electoral del Estado de México.

Domjan, M. (2010). Principios de aprendizaje y conducta. México, Wadsworth, Cengage Learning.

Dustmann, Ch. y Kirchkamp, Ol. (2001). The Optimal Migration Duration and Activity Choice After Re-migration. En Journal of Development Economics, (67), 351-372.

Estrada, M. (2008). Diferencia que hace diferencia. Migración y organización familiar. En Desacatos, (28), 89-100. México, CIESAS.

Instituto Nacional de Estadística y Geografía [INEGI] (2016). Encuesta Intercensal 2015. México, INEGI.

Izcara, P. (2010). Redes migratorias o privación relativa: la etiología de la emigración tamaulipeca a través del programa H-2 ${ }^{\mathrm{a}}$. Relaciones, XXXI (122), 245-278. Zamora, El Colegio de Michoacán.

Kirdar, M. (2007). Labor market outcomes, capital, accumulation, and return migration: Evidence from immigrants in Germany, MPRA (Minich Personal RePEc Archive). http://mpra.ub.uni-muenchen.de/2028/

Long, N. (2007). Sociología del desarrollo: una perspectiva centrada en el actor. San Luis Potosí: El Colegio de San Luis.

López, G. (2003). Diáspora, circulación y movilidad: notas desde Michoacán. En López, G. (Coord.). Diáspora michoacana (pp. 19-31). Zamora El Colegio de Michoacán/ Gobierno del Estado de Michoacán. 
Murphy, R. (2000). Return Migration, entrepreneurship and local state corporatism in rural China: the experience of two counties in south Jiangxi. Journal of contemporary China, 9(24), 231-247.

Ranciere, J. (2010). Dissensus: On politics and aesthetics. London: Continuum.

Reichert, J. (1981). The migrant syndrome: seasonal U.S wage labour and rural development in central Mexico", Human Organization, 40(1), 56-66.

Robbins. S. y Judge. T. (2009). Comportamiento Organizacional. México, Prentice Hall.

Salas, R., y Cruz. M. (2014). Migrantes retornados, actividades laborales y nuevas habilidades adquiridas en San Miguel Coatlán, Oaxaca, Puebla, Universidad Popular Autónoma del Estado de Puebla.

Simon, H. (1995). The Information Processing Theory of Mind. American Psychologist, 50(7), 507-508.

Simon, H. (1962). Discussion: problems of methodology. American Economic Review, (53), 229-231.

Stark, O. (1982). Research on Rural to Urban Migration in ldcs: the Confusion Frontier and Why We Should Pause to Rethink Afresh. World development, $10(1), 63-70$.

Stark, O., y Taylor, E. (1991). Migration incentives, migration tipes: the role of relative deprivation. The Economic Journal, 101(408), 1163-1178. Royal Economic Society.

Zwania, I. (2013). Returning Migrants in Cameroon Challenges, Obstacles and Potentials. En Zwania, I., y Vanya, I. (Eds.). ¿ Welcome home? Challenges and chances of return migration (pp. 19-28). Bulgaria: Transatlantic Forum on Migration and Integration. 